\title{
Commensurability of Human and Web Resources Scale in Development of Socio-Cultural Systems
}

\author{
Eleonora Barkova $^{1 *}$, Marina Ivleva ${ }^{1}$, Olga Buzskaya, ${ }^{1}$ and Marat Buzsky $^{2}$ \\ ${ }^{1}$ Department of History and Philosophy, Humanitarian Training Centre, Plekhanov Russian University of Economics, Moscow, \\ Russia \\ ${ }^{2}$ Department of Philosophy, Volgograd State University, Volgograd, Russia
}

\begin{abstract}
The purpose of this article is to study the correlation of human resources and web resources in the current stage of the information society development through the prism of intersubjective relations in a communicative environment. As methods of research, the authors used methods of comparative analysis and data synthesis, based on the anthropic principle and holistic philosophical methodology. This article analyzes the specifics of the modern information space and concludes that the focus of the space-time continuum of the modern world is the practical and theoretical development of Web resources and related forms of worldview. In these conditions, when the Web-space is not able to disclose the inner experience of the individual, its existential dimension, the task of restoring the subject as the center of the socio-cultural space that sets and transmits information becomes urgent. One of the most important means of solving this problem is the reflection of information ecology, within which human and Web resources interacting represent a whole in which all types of human activity and communication are realized and express the initial relation of the subject and the object, the person and his object environment.
\end{abstract}

\section{Introduction}

Nowadays the expansion of the information and communication space has acquired such a pace, scope and role in regulating all sociocultural processes, that it is legitimate to cover the question of whether the development of human subjectivity is exhausted. Can a traditional subjectivity of a subject be changed or replaced by information and socio-technical systems, which form today a worldwide network of innumerable communication flows, programs and management codes - the Web network - in the space of which projects support the relative stability of the entire world order and its ability to react instantly for any changes? Or a human has still an inexhaustible and basic resource potential for renewal of planetary being, communities, culture and the unique world of a mankind?

The processes of active development of the information and communication space have become the subject of studies showing a wide range of assessments of various factors in the information society and its economic (F. Machlup), cultural (J. Baudrillard, Z. Bauman), technological (Z. Brzezinski) vectors. F. Machlup can rightly be considered as the founder of the scientific reflection of the developing information society. He stated the idea that in modern social conditions knowledge becomes a commodity, and considering the fact that twenty-nine percent of the gross national product in the USA in the early 1960s amounted to production results and distribution within the knowledge industry, it can be argued about the onset of a new, information era (Lumiansky and Machlup, 1963)

According to Jean Baudrillard, one of the most famous representatives of postmodernism, there is "more and more information in the society, and less and less meaning" (Baudrillard, 1994)]. In comparison to previous eras, now the diversity of signs and symbols in social and individual life led to the decline and even the collapse of a meaning itself. Instead of a stable value that the signs had earlier (for example, clothing symbolized a certain status, and the politician's speech is a certain philosophy, a world outlook), at present they are so diversed and have come from such different directions, forming a chaotic "amazing web", they change so quickly and contradictory, that one can easily rethought them, change the meaning, interpret and reinterpret.

In the assessments of the cultural space of the modern information society, opposing positions are presented, starting with extremely optimistic, as, for example, T. Stonier, according to which the information society is an era of abundance, where "everyone is an aristocrat, everyone is a philosopher". (Stonier 1983). Other researchers held more restrained assessments. Along with the well-known critics of technocracy, Neil Postman, who researched the information society in its ontological and axiological aspects, has showed that under conditions of accelerated information exchange, not only relevant to the prospects of socioeconomic life

* Corresponding author: barkova3000@yandex.ru 
is important for a person, but something that simply has novelty. (Postman 2014). Without denying the importance of information and significance of the technological development for society, Postman pays attention to those threats to the existence of the human personality that exist in the modern information world and appear due to the fact that the individual ceased to be the most important value in it. This place in the current culture was taken by information as such.

Innovation technologies and means of information transferring are created primarily for the purpose of generating, storing and distributing data of large volumes from an unprecedented speed. When asked what problem the information solves, the answer is: "how to receive and distribute as much information as possible, which would be faster and more convenient for the consumer". As a result, information gains a metaphysical status as the means and purpose of human creativity. The scientist notes as well, that we are used to living life in search of access to information, without hesitation, what is the purpose of obtaining information and what kind of information this should be (Postman 1993).

Many researchers justly point out virtual reality as a specific ontological component of the modern communicative space (Ponizovkina, Agibalova 2016, Shukshina L. et al., 2017), wondering what effect it has on a person, what is the ratio of the positive and negative consequences of the fact that virtual reality is now virtually inseparable from modern social life. Thus, $\mathrm{M}$. S. Cline believes that the construction of a virtual space is an important element of modern social engineering that improves the quality of human life. Social "macroengineering," in his opinion, affects the dynamics of social groups, and "microengineering" can be used to influence the individual, his or her social position, thoughts, patterns of meaningful behavior, interpersonal communication. Virtual reality can develop such qualities of the individual as independence, ability to control the environment, ability to set long-term goals of activity, and also help balance the relationships between other people and individual autonomy (Cline 2005). The logic of the development of society, according to Cline, is the gradual "migration" of mankind into virtual space, which will become an important tool for social contacts, communication, education, recreation and games, and where people spend most of their time. This will lead to the emergence of a "transhuman race" when, using new technologies, mankind will improve its body and mind, and then the "posthuman" race, due to biological and psychological modifications and loss of contacts with the traditional physical world, and, consequently, the individuals' abandonment of the traditional biological and cultural world.

\section{Problem Statement}

We believe that the current situation and impressive innovations in the info-technosphere, in which the opportunities for reduction of planetary integrity to local forms of subject practices were manifested, reflects the real backwardness of modern mankind from mastering the multidimensionality and scale of its planetary subjectness that did not open up to the modern era of a common cultural form with its subject-communicative and cultural-symbolic manifestations (Barkova 2016). Therefore, subjectivity and a person as a resource and the value of culture for the most part of the subjects likely does not exist.

This backlog has already generated a lot of contradictory assessments: the dehumanization of society and personality, the decline in the status of culture and education, the spread of instrumental and technocratic orientations of subjects that manifest themselves not only in the processes of making lifesupporting decisions, in communication as well, but also in the dominant forms of self-awareness and mass culture. Today, the interpretation of human resources and human capital connects them only with the needs of corporate space, production, with the quality of the firm's personnel, actually tying human resources - albeit indirectly - to information and Web resources.

\section{Research questions}

In the modern informational world, where active involvement of individuals in the web space is the inseparable fact of everyday life, and virtual reality is very popular, can we say that the web space is an expression of human subjectivity? Is it possible that a person can realize his / her personality in the web space to the same limits as in the immediate physical social reality or in the space of culture? Or, vice versa, a person, realizing himself as a web resource, loses himself as a traditionally human resource?

\section{Purpose of the Study}

The purpose of this article is a comparative analysis and clarification of the ratio of human resources and web resources in the current stage of the development of the information society through the prism of intersubjective relations in a communicative environment. Currently, the criticism of the absolutization of the positive aspects of the modern information society and the communication culture continues, calling for the preservation of humanistic landmarks in the development of sociocultural systems, but today it is important, after making the next step, to try and compare the specifics of the space of Web resources and human resources from the ecophilosophical positions of preserving life on Earth, vitality, the further life-creation of mankind.

\section{Research Methods}

Using the ecophilosophical approach based on the cosmoplanetary worldview to analyze the problem of the ratio of human resources and web resources in the modern information space, the authors examine the problem of human subjectivity in the conditions of web communications. 
When writing this article, the authors have based on the holistic philosophical methodology and used methods of analysis and synthesis of data, both previously obtained by previous researchers, and the conclusions of the authors; as the starting points of the research there are the concepts of a human as a subject of information and communicative space, communicative space as an integrated multi-level system, the integrity of human ecology as a person in the context of the unity of the individual, society and nature.

The leading methodological principles in this study are the principles of the wholeness, integrity and systemic nature of the world, its internal unity, as well as the concept of an ecophilosophical picture of the world from the perspective of which the subject's problem in the web space is explored.

\section{Findings}

Even in the second half of the twentieth century, theorists pointed to the resource significance of information, the fact that the transition to an information society, which E. Toffler revealed, "encompasses morals, culture, ideas, as well as the institutional and political structure of society. It means a genuine transformation of the whole human life. "(Toffler 1990). And since, as shown by M. Castells, as the concept of the network society focuses on the assumption that information becomes the basis of social organization, it forms the new social morphology due to the fact that social structures are represented in it as network structures. (Castells 1996). The information space and its elements - "site atoms" in their interaction, as it were, opened new layers of the life of modern humankind. Billions of simultaneous contacts via Internet channels, the instantaneous dissemination of relevant news, the formation of an immeasurably more complex hypertext, in which not only projects, norms, values, but also conditions of communications in the global space of life - from economics, science, finance, management to ethics, all this has put into the center of the space-time continuum of the modern world the practical and theoretical development of Web resources and the associated forms of worldview.

But the successes and achievements of the practical development of the expanding Web space and its resources do not imply its self-awareness as an activity, i.e. going beyond borders from the standpoint of culture - the "parameter" in which there is a person as a subject. As a result, the analysis of Web resource artifacts already reveals, first, their object status and alienation from human subjectivity and, secondly, the fact that the explosion-like acceleration of the possibilities and changes in the network messages and their content prevents them from deep comprehension, only superficial knowledge and associations. Thus, the web space as it rolls inward, pushing subjects "out." The accumulation of information and the expansion of the space of contacts are the basic directions of implementing Web resources (Mitin, et al. 2017, Inozemtsev, et al. 2017). And although new technologies, forms and models of computer designing are created on this basis, on the whole, the world of people's being, their ability to deep unhurried experiences, compassion, shame, friendship turns out to be more and more superficial, "flat", since the real in this coordinate system turns out to be not the person himself, but his standardized communicative model. Hence - the growth of "clip-on thinking" and significant transformations in the processes of socialization and learning. Oriented to the external perception of images and texts, the Web space is not able to reveal the inner experience of the individual, its existential dimension, as a result of which the further development of technology, the reification of reality and the unique robotization of life are the prospects for the growth of the Web resources space.

Other perspectives on the basis of modern ecophilosophy reveal an organically integrated, comprehensively mastering of human resources, reviving the ancient concept of understanding man as a microcosm. First of all, today it is very important to restore its substantial-human definition (Barkova, Ivleva, Buzskaya and Buzskij 2017). Human resources are, by definition, the unfolding of the potential of freedom (Ponizovkina 2017, creativity, measure and harmony of man, nature, culture and cosmos. This space is the development of intersubjectivity, intersubject, intercultural dialogues and polylogues, but the main thing is the restoration of the conditions of the basic - the cultural existence of man as the basis for the revival of the priority of the subjective beginning in the modern world, including the processes of globalization.

But then we can see the problem of assessing the intrinsic space of this intersubjectivity as a key resource of mankind. In history, as we know, a number of forms of such a space have been worked out: myth, religion, art, ideology. Obviously, this space can not in itself be material-objective: it exists as a regulative principle, an ideal, but has no attributes of objects, it is subjective. It is this that expresses the ontological dimension of man's resources as a subject. But none of these forms today has revealed the necessary and sufficient potential of man because in them the subjects are not converted in their freedom, to the "big" world and the microworld microcosm - to themselves.

That is why today we need an essentially renewed planetary-subject space in which the resources of mankind and its forms of interaction with nature based on reason are guaranteed and consistently disclosed. Therefore, a space of an ecophilosophical picture of the world can become a promising conceptual space that reveals and preserves the resource of man and mankind as a source of life-creation. In the space, the existence of a human as an initial and main category and value, is distanced from pragmatic attitudes, which in different modifications are already linked to the Web resources. In this perspective, a measure of the commensurability of human resources and Web resources is revealed only in the local processes of human existence and incommensurability in the space-time of being.

The condition for the revival of attention to the subject as the center of the socio-cultural space of the 
information society is the reflection of information ecology. First of all, we are talking about the regulation of spontaneous information flows today-their valuecultural restriction and "clean-up" of information garbage in accordance with the society's need for selfidentification and the preservation of high values and ideals as the basis for developing self-awareness (Agibalova, Barkova and Ivleva 2017). In the course of history, subject-object communication as a special space, and today - and as a special value, - was preserved at all stages of world history and in all epochs. And it is the subjects, including society, and from the beginning of the 20th century, humanity as a subject, has always developed a relation to information as an object, thereby removing the appearance of information self-regulation. Undoubtedly, information is a special object, one that in some respects approaches a subject in the performance of his function - the translation of content. But information only imitates the role of the subject: in its meaning it can never fully realize it, because the subject as the source of information is the creator of the birth of such attitude to the world as freedom, values and evaluation, choice and limitation, discrimination of the possible and actual, space and time, etc.

The preservation and restoration of the initial "point" - the subject as the center of socio-cultural space, which sets and translates information as a condition for the continuity of the evolution of human history and culture, and, in turn, the definition of information as a peripheral category - is the only way to understand information as an object and to overcome the illusion of its selfsufficiency in modern society.

\section{Conclusion}

Thus, today's significant advance in the development and development of the Web-based resource network in relation to the human resource does not mean that these two important resource sources mutually limit each other or are oppositely directed in their nature. Both of them express the initial relation of the subject and the object, the person and his object environment. These parties interact, because they represent the whole, in which all kinds of human activity and communication are carried out. But this simultaneously means that the ratio of Web resources to the main resource, which carries humanity, also retains this common basis: the development of the resource of modern humanity is an object-oriented development of the Web space. But since it is organically connected with the space of being and human life, such development, of course, opens the further way of mastering by mankind of itself, its infinite, unlimited, although insufficiently researched resources.

\section{References}

1. R. Lumiansky, F.Machlup, AAUP Bul., 49(3), 277 (1963)

2. J. Baudrillard, In the Shadow of the Silent Majorities (A.K. Press 1994)
3. T. Stonier, The wealth of information: a profile of the post-industrial economy (London 1983)

4. N. Postman, Amusing ourselves to death (New York, Penguin Books 2014)

5. N. Postman, Technopoly: The Surrender of Culture to Technology (New York, Vintage Books 1993)

6. I. Ponizovkina, E. Agibalova, Proceedings of the 2016 International Conference on Contemporary Education, Social Sciences and Humanities, 657662 (2016)

7. L.V. Shukshina, Y.V. Bazhdanova, I.A. Koretskaya, B.S. Vasyakin, N.V. Lipatova, Eur. J. of An. Chem. V. 12. № 5b, 875-885 (2017)

8. M.S. Cline, Power, madness and immortality: the future of virtual reality (Seattle, University Village press 2005)

9. E.V. Barkova, Socio-human. Knol, 8, 241-248 (2016)

10. A.Toffler, The Third Wave (New-York, Bantam Books 1990)

11. M. Castells, The Information Age: Economy, Society and Culture: The Rise of the Network Society (Oxford, Blackwell 1996)

12. S.N. Mitin, L.V. Shukshina, Y.V. Bazhdanova, I.A. Koretskaya, B.S. Vasyakin, Eur. J. of An. Chem. V. 12. № 7b, 1193-1200 (2017)

13. V. Inozemtsev, M. Ivleva, V. Ivlev, Proceedings of the 2017 2rd International Conference on Contemporary Education, Social Sciences and Humanities, 1151-1157 (2017)

14. E. Barkova, M. Ivleva, O. Buzskaya, M. Buzskij 2nd International Conference on Contemporary Education, Social Sciences and Humanities, 12-15 (2017)

15. Ponizovkina, Proceedings of the 2016 3rd International Conference on Education, Language, Art and Inter-cultural Communication, 648-653 (2017)

16. E. Agibalova, E. Barkova, M. Ivleva, Proceedings of the 2017 2nd International Conference on Contemporary Education, Social Sciences and Humanities, 1146-1150 (2017) 